\title{
Unusual Case of Foreign Body Esophagus Presenting With Acute Kidney Injury: Case Report and Literature Review
}

\author{
Sudha Shahi ${ }^{\mathrm{a}, \mathrm{c}}$, Tika Ram Bhandari ${ }^{\mathrm{b}}$, Tridip Pantha ${ }^{\mathrm{a}}$
}

\begin{abstract}
Foreign bodies in esophagus are more common in children, elderly and psychiatry patients. Different types of foreign bodies can get impacted in esophagus, such as coins, bone pieces and meat bolus. Approximately $80 \%$ of foreign bodies are said to pass spontaneously without any intervention. Emergent endoscopic retrieval or rigid esophagoscopy are the treatment of choice. Delayed diagnosis can lead to respiratory failure, sepsis or hemorrhage. Nevertheless, esophageal foreign bodies are no more matter of serious concerns to the surgeons in terms of early diagnosis and management given the advancement in the diagnostic tools. Eventually delayed management and complications due to prolonged foreign body impaction are less in the picture nowadays. Here we present a typical case of foreign body esophagus that presented with acute kidney injury which was delayed to reach help due to various factors, such as poor economic background of the patient, poor access to health service and prevalence of social beliefs. Cases of complications like respiratory failure, sepsis, mediastinitis and hemorrhage have been reported very frequently, but cases presenting with acute kidney injury seem to be reported very less in literature. Thus, we believe that this case will add acute kidney injury to another possible complication of delayed foreign body esophagus.
\end{abstract}

Keywords: Foreign body; Esophagus; Acute kidney injury; Complications; Social beliefs

\section{Introduction}

Foreign bodies in esophagus are common clinical problem. It is relatively more common in children, elderly, psychiatric patients and prisoners. Management principles are based upon the nature of the foreign bodies and the site of impac-

Manuscript submitted September 12, 2018, accepted September 24, 2018

aDepartment Of Otorhinolaryngology Head and Neck Surgery, National Academy of Medical Sciences, Bir Hospital, Kathmandu, Nepal

bDepartment of General Surgery, People's Dental College and Hospital, Kathmandu, Nepal

${ }^{\mathrm{c} C}$ Corresponding Author: Sudha Shahi, Department Of Otorhinolaryngology Head and Neck Surgery, National Academy of Medical Sciences, Bir Hospital, Kathmandu, Nepal. Email: sudashahi@gmail.com

doi: https://doi.org/10.14740/wjnu366 tion. Different types of foreign bodies encountered are coins, bone pieces, nails, button batteries pieces of glass, dentures, small toys, pins and needles, etc. [1]. Esophagus has few areas of physiological narrowing where a foreign body might get impacted more frequently: 1) cricopharyngeus, 2) level of aortic arch and 3) lower esophageal sphincter [2]. Studies have shown that cervical esophagus is the commonest site for foreign body impaction, while the complications that follow in order are upper thoracic esophagus, pyriform fossa and valeculla [3]. Characteristically, the patient presents to an emergency department with chest or throat discomfort, dysphagia, odynophagia and/or difficulty managing oral secretions [4]. Approximately $16.7 \%$ of esophageal perforations are related to foreign body ingestion. Respiratory failure, sepsis or hemorrhage might be caused in the case of delayed diagnosis and treatment [1]. Thus, early and accurate diagnosis is valuable for the management. Eighty percent do not require any intervention [5]. Endoscopic removal has emerged as one of the important procedures for removal of majority of foreign bodies requiring intervention [6]. Other equipments including snares, nets and baskets can also be used under direct visualization [2]. There has been a significant achievement in management techniques since 1947. This has helped minimize the complications with the help of advanced instruments, anesthetics and skilled manpower. Management of foreign bodies has been made possible by introduction of suture technique, double snare technique, combined forcep and snare technique for long and sharp foreign bodies, retrieval nets and many specialized forceps [7].

\section{Case Report}

A 45-year-old man presented to the emergency department with a history of odynophagia for 12 days. It was sudden on onset preceded by a history of ingestion of chicken bone and one episode of vomiting. He had not been able to take solid diet for the past 10 days, while he was on semisolid diet for the first 2 days after the incident and then was gradually on liquid diet for next few days. For the past 3 days, he had difficulty in swallowing liquid too. There was associated history of fever for 7 days which was continuous in nature $\left(\mathrm{T}_{\max }\right.$ not recorded) with chills but no rigor. There was no aggravating factor, but it was relieved on taking antipyretics. He also gave a history of mild shortness of breath upon exertion, difficulty in speaking, but denied any history of cough, chest pain, palpitations and neck trauma. He also gave a history of generalized weak- 

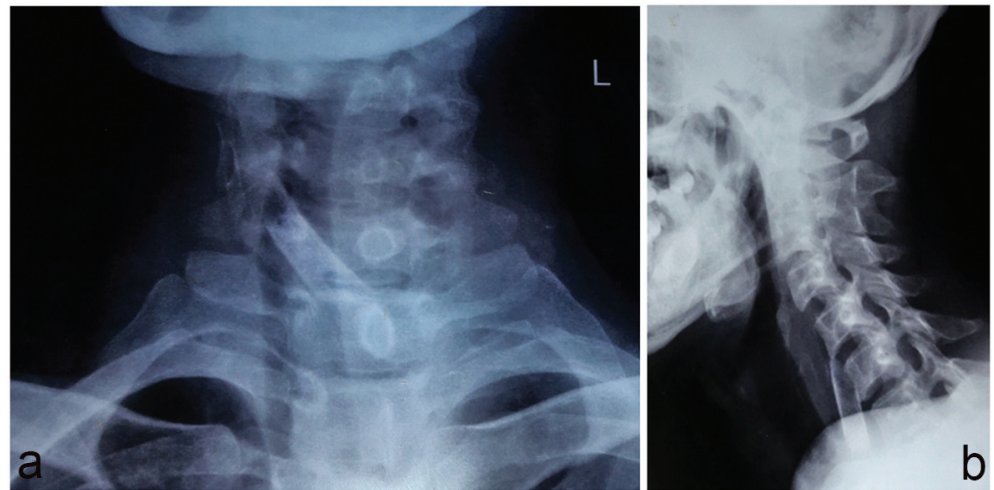

Figure 1. (a) Plain X-ray AP view showing radioopaque shadow. (b) Plain X-ray lateral view showing radiopaque shadow from C5 to $\mathrm{C} 7$ level.

ness and increased thirst. He had decreased urine output for the last 3 days and had not passed stool for the same duration of time, but was passing flatus. He denied any history of medical illness or surgery. Family history was not significant. For the same illness on the third day, they had visited a small health center nearby where he was managed conservatively for pain with some analgesics and was kept under observation for 1 day and discharged. Again on the seventh day, due to worsening of symptoms, they went to a spiritual healer where they spent another 2 days performing some rituals and offering prayers. Finally, when nothing seemed to work, the patient was taken to the primary health center which was at a distance of 6-h walking. Finally, with the suspicion of foreign body oesophagus after initial IV resuscitation, he was referred to a higher center $12 \mathrm{~h}$ by a local transportation and finally landed to our emergency room on the 12 th day.

On examination, the patient looked toxic and dehydrated. His voice was muffled. His blood pressure was 100/50 mm Hg, and pulse rate was $110 / \mathrm{min}$ regular with low volume. His temperature was $102{ }^{\circ} \mathrm{F}$. His white blood cell (WBC) count was $14,000 \mathrm{mg} / \mathrm{dL}$. His blood urea was $91 \mathrm{~g} / \mathrm{dL}$, while creatinine was $2.1 \mathrm{~g} / \mathrm{dL}$. There was no abnormal finding in the oral cavity. Indirect laryngoscopy revealed positive Chevalier Jackson's sign. There was fullness over anterior aspect of neck. There

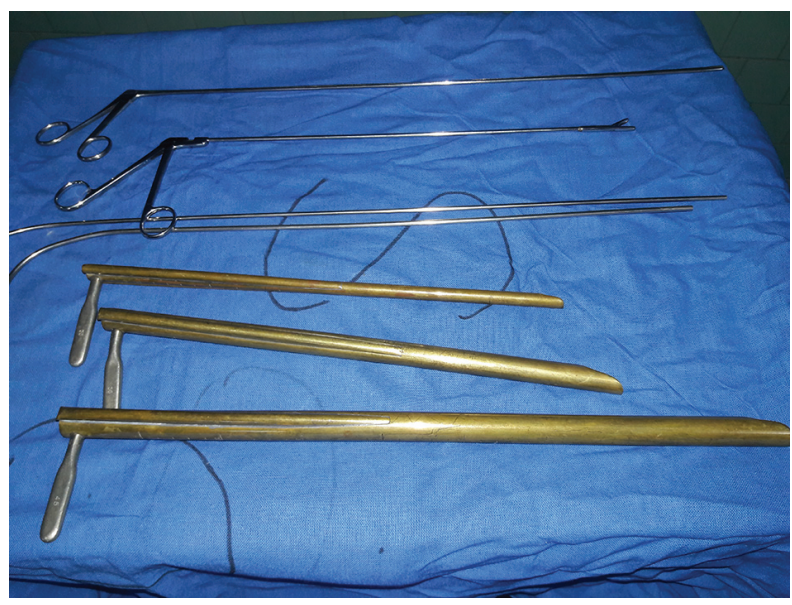

Figure 2. Figure showing rigid esophagoscopes. was a rise of temperature and tenderness on palpation. Lymph nodes were not palpable. X-ray soft tissue neck lateral and AP views revealed a huge radiopaque foreign body extending from the level of lower border of C5-C7 vertebra (Fig. 1). There was no free air in mediastinum.

Initial resuscitation was done and he was started on IV antibiotics. Department of nephrology was consulted for acute kidney injury and was planned for dialysis if renal function tests did not improve. However, the next day his renal functions showed signs of improvement. He was then planned for direct esophagoscopy using rigid esophagoscope (Fig. 2) after clearance from anesthesiologist. During esophagoscopy, a foreign body (piece of bone) was visualized beneath upper esophageal sphincter at a distance of $16 \mathrm{~cm}$ from upper incisors in an oblique fashion impacted over the left side of esophageal wall measuring about $4 \times 1 \mathrm{~cm}^{2}$ (Fig. 3). There was mucosal edema with purulent secretions. Foreign body was then grasped by grasping forcep and rotated to the midline and brought inside the esophagoscope and removed. But due to extensive mucosal edema, there was small laceration over the foreign body impaction site. Immediate postoperative period was uneventful. The patient was kept NPO till $48 \mathrm{~h}$. Nasogastric feeding was started for next $48 \mathrm{~h}$. He was on regular IV antibiotics and analgesics. Plain radiographs were repeated over the next day which came normal. Upper gastrointestinal endoscopy was repeated 2 days later and there was no incidence of major injury to the esophagus. Nasogastric feeding was removed and oral feeding was started which was uneventful. His subsequent re-

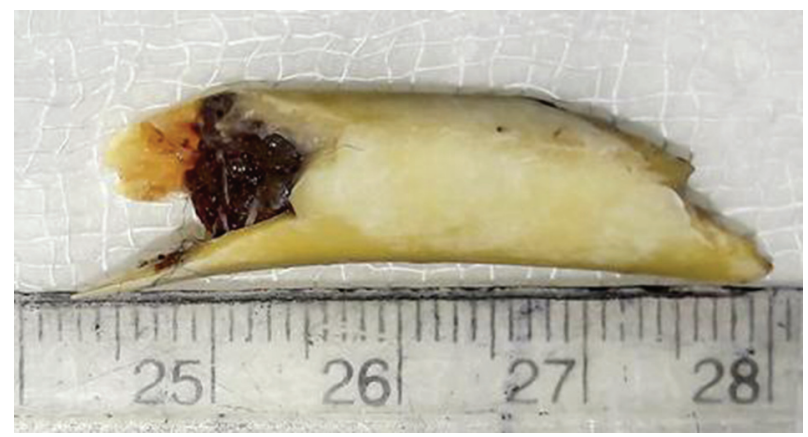

Figure 3. FB (chicken bone). 
nal function tests were normal. The patient was sent home on the seventh postoperative day.

\section{Discussion}

A foreign body in the esophagus is more common among children, elderly or people with mental or neurological disorders [8]. It has estimated annual incidence of 11 per 100,000 persons in the USA [9] and accounts for up to 1,500 deaths per year [10]. Severity of symptoms depends upon size, type, site and period for which foreign body has been lodged [1]. Complications occur more commonly in adult populations. They include and are not limited to perforation leading to retropharyngeal abscess, subcutaneous emphysema, mediastinitis, retroesophageal abscess, lung abscess, esophagoaortic fistula, trachea esophageal fistula, etc. [11]. Clinically, it can cause acute onset of dysphagia and odynophagia along with chest pain, feeling of compression at chest and laryngeal irritation [12]. Size, site and nature of foreign body are of importance. Variable according to age, the most difficult is upper cervical region [13]. Foreign bodies can be categorized according to their physical characteristics which might be small and blunt, sharp or pointed, or long. Any foreign body in the esophagus should be removed since they possess a risk of pressure necrosis and resultant perforation. Sharp or long objects carry a risk of perforation of $15-35 \%$; thus, they should be removed regardless of location [2] However, some suggest that foreign bodies passed into the stomach can be usually observed for development of symptoms since $80 \%$ pass spontaneously. Diagnosis is based upon clinical history, confirmation by plain radiograph or CT scan and upper GI endoscopy. Most foreign bodies can be visualized by plain radiographs of AP and lateral view of neck [5]. However, some foreign bodies cannot be visualized by plain radiographs. Barium radiographs might be helpful in such cases. CT scan is more valuable to confirm localization and interaction with adjacent tissues [14]. In our case, delay in diagnosis was due to inaccessibility of radiography service and skilled manpower. Above all, the poor economic background of the patient, social taboos and geographic constrain were all playing their roles in delaying of the diagnosis and proper management. In almost all the cases, endoscopy is preferred. It is safe as well as diagnostic and therapeutic. It is generally performed under sedation. Endotracheal intubation and general anesthesia may be needed in the case of psychiatry patient and if the foreign body is difficult [15]. Rigid esophagoscopy under general anesthesia may be required in foreign bodies that can not be removed by flexible endoscope or large foreign bodies. In our case, foreign body was removed successfully by using rigid esophagoscope. Laparoscopic approach is mandatory where endoscopic approach fails [16].

\section{Conclusions}

Prompt assessment of esophageal foreign bodies is of utmost significance in terms of management. Radiological evaluation before removal is indicated to confirm diagnosis of foreign body. Plain radiographs are one of the important tools to identify localization of foreign body. Emergent endoscopy is an important part of management. But poor access to an equipped health facility might delay the management of the patient leading to fatal consequences.

\section{Conflict of Interest}

The authors declare no conflict of interests.

\section{Financial Support}

No funding or grant was used for this report.

\section{Ethical Approval}

This is a case report, so exemption has been provided.

\section{Informed Consent}

Both informed consent and written consent were obtained from the patient.

\section{Abbreviations}

FB: foreign body; LES: lower esophageal sphincter; C5: cervical 5; C7: cervical 7; NPO: nil per oral; NG: nasogastric; IV: intravenous; GI: gastrointestinal; USA: United States; AP: anteroposterior; CT: computed tomography

\section{References}

1. Verma PC, Gaur A, Singhal AK. Neglected foreign body in oesophagus with an unusual presentation: A case report. Indian J Otolaryngol Head Neck Surg. 2006;58(1):89-90.

2. Flint PW, Haughey BH, Robbins KT, Thomas JR, Niparko JK, Lund VJ, Lesperance MM. Cummings Otolaryngology-Head and Neck Surgery E-Book. Elsevier Health Sciences; 2014 Nov 28.

3. Nandi P, Ong GB. Foreign body in the oesophagus: review of 2394 cases. Br J Surg. 1978;65(1):5-9.

4. Crockett SD, Sperry SL, Miller CB, Shaheen NJ, Dellon ES. Emergency care of esophageal foreign body impactions: timing, treatment modalities, and resource utilization. Dis Esophagus. 2013;26(2):105-112.

5. Vijaysadan V, Perez M, Kuo D. Revisiting swallowed troubles: intestinal complications caused by two magnets - a case report, review and proposed revision to the algorithm for the management of foreign body ingestion. J Am Board Fam Med. 2006;19(5):511-516.

6. Palta R, Sahota A, Bemarki A, Salama P, Simpson N, Laine L. Foreign-body ingestion: characteristics and 
outcomes in a lower socioeconomic population with predominantly intentional ingestion. Gastrointest Endosc. 2009;69(3 Pt 1):426-433.

7. Kay M, Wyllie R. Pediatric foreign bodies and their management. Curr Gastroenterol Rep. 2005;7(3):212-218.

8. Cangir AK, Tug T, Okten I. An unusual foreign body in the esophagus: report of a case. Surg Today. 2002;32(6):523524.

9. Longstreth GF, Longstreth KJ, Yao JF. Esophageal food impaction: epidemiology and therapy. A retrospective, observational study. Gastrointest Endosc. 2001;53(2):193198.

10. Lai AT, Chow TL, Lee DT, Kwok SP. Risk factors predicting the development of complications after foreign body ingestion. Br J Surg. 2003;90(12):1531-1535.

11. Maglinte DD, Taylor SD, Ng AC. Gastrointestinal perforation by chicken bones. Radiology. 1979;130(3):597599.

12. Committee ASoP, Ikenberry SO, Jue TL, Anderson MA,
Appalaneni V, Banerjee S, Ben-Menachem T, et al. Management of ingested foreign bodies and food impactions. Gastrointest Endosc. 2011;73(6):1085-1091.

13. de Lucas EM, Ruiz-Delgado ML, Garcia-Baron PL, Sadaba P, Pagola MA. Foreign esophageal body impaction: multimodality imaging diagnosis. Emerg Radiol. 2004;10(4):216-217.

14. Ghahremani GG, Yaghmai V. Foreign bodies of the alimentary tract. In: Textbook of Gastrointestinal Radiology. 2nd edition. WB Saunders, Philadelphia; 2000; 21962205.

15. Gmeiner D, von Rahden BH, Meco C, Hutter J, Oberascher G, Stein HJ. Flexible versus rigid endoscopy for treatment of foreign body impaction in the esophagus. Surg Endosc. 2007;21(11):2026-2029.

16. Furihata M, Tagaya N, Furihata T, Kubota K. Laparoscopic removal of an intragastric foreign body with endoscopic assistance. Surg Laparosc Endosc Percutan Tech. 2004;14(4):234-237. 